\title{
NOTE ON THE SULCUN IUNATUS IN NEGRO AND WHITE BRAINS AND ITS RELATION TO THE AREA STRIATA
}

JAMES B. MURPIIY

From the Anatomical Laboratory of the Johns IIopkins University

WITH SIXTEEN TEXT FIGURES

The recent critical work of Professor Mall ${ }^{1}$ on the evidences of any racial characteristic of the brain that can be made out by our present methods, involving as it does both his own work and an analysis of the evidence in the literature, must make one skeptical of results that are positive in their nature.

Probably no area of the cortex has been subjected to so much study as the occipital cortex, in the hope of some evidence of racial characteristics. In 1904 Elliott Smith $^{2}$ suggested a method of study of the occipital lobe which appeals to reas $n$ as being a little less crude than the methods of weighing and comparing surface form and folds, and one that yielded Professor Smith results which stimulate a further application of the method. The method in a word is this: the histological picture of the cortex in the calcarine region, namely, the visual area, is sufficiently marked to be distinguished in thin, freehand sections of a fresh brain, or of a brain hardened in formalin. The characteristic of this area is the so-called stripe of Gennari or line of Vicq d'Azyr. This stripe is readily seen with the naked eye and Smith pointed out that its limits are sharp rather than indefinite, so that it is not necessary to stain sections for fibers by the Weigert method in order to mark out the area striata. Having marked out the area striata by means of freehand sections, he studied the sulci of the calcarine area

'Mall. On several anatomical characters of the human brain, said to vary according to race and sex, with especial reference to the weight of the frontal lobe. Amer. Journ. of Anat., vol. 9, 1909.

${ }^{2}$ Smith. Morphology of the retro-calcarine region of the cortexcerebri. Studies in morphology of the human brain. No 1. The oceipital region. Records of Egyp1, Gov. School of Med., vol. 11, 1904. New studies of the folding of the oecipital sulei in human brain. Journ. of Anal. and Physiology, vol. 41, p. 198, 237. 
from the point of view of their relations to the area striata. In the following points, which can be seen in fig. 1, Smith sharpens our definitions of the region (fig. 1-A.) The calcarine fissure, making the well-known stem of the $\mathrm{Y}$, forms the limiting anterior boundary of the area striata in most human brains, which agrees with the findings of both Flechsig ${ }^{3}$ and Campbell. ${ }^{4}$ Its corresponds to the calcar avis and is primitive in type. Its developmont corresponds to the differentiation of the cortex of the area (fig. 1-B.) The continuation of the calcarine fissure, namely, the retrocalcarine sulcus, is to be defined as a sulcus within the area striata, not bounding it, and the foldings of the area striata into retrocalcarine sulci is subject to great variations (fig. 1-C). The retrocalcarine sulcus usually extends around the occipital pole from the mesial surface to the lateral surface. This extension has been well-named by Cunningham, the external calcarine sulcus. Likewise, the area striata, surrounding this external calcarine sulcus, extends around the pole of the occipital lobe to the lateral surface of the brain and usually comes into relation to a curved sulcus, which Smith calls the lunatus, the homologue of the Affenspalte.

This study was begun to test the relation of the area striata to the sulcus lunatus, which it will be seen is a reaching out toward comparing the histological structure of different brains. The number of brains studied has been extremely small, but since the work is unavoidably interrupted for a few years, it was deemed best to publish the results that have been obtained.

The sulcus lunatus Professor Smith considers definitely related to the area striata. To quote his words: "In all mammals (with the exception of man in some cases) the stripe of Gennari extends to the lateral aspect of the hemisphere. In apes, and in most cases in man also, the anterior crescentic edge of this area striata pushes itself forward in such a manner that a deep cleft, a simple sulcus or a mere pucker is formed in front of the advancing

\footnotetext{
${ }^{3}$ Flechsig. Ueber Untersuchungs-methoden der Grosshirnrinde. Berichte math-phys. Klasse d. K. Sachs. Gesellschaft, leipzig, 1904, and Arch. f. Anat. u. Phys., Anat. Abt. 1905. Presis.

*ampleil. The Localization of corebral function. Cambridge IIniversity
} 
edges, like a trough in front of a wave. This trough is often bridged by one or several folds separating the deeper parts one from the other . . . The sulcus lunatus is a depression formed by the forward projection of the cortical area containing the striata of Gennari." It is found in many forms and positions on the surface of the brain.

The material for this work was selected at random from the collection in the anatomical department of the Johns Hopkins University. The drawings were made and the area striata was plotted before the records of the race were looked up, in all but one or two cases in which brains were chosen to even up the series, so as to rule out the personal equation as much as possible. There were however no records kept in the department to show the type of negro, whether full-blooded or mulatto. The drawings are geometrical tracings, made by means of the very accurate projecting apparatus made by Hermann of Zürich. Great care was taken to get the brains in as uniform a position as possible. In plotting the area striata, very thin sections were made with a razor, perpendicular to the surface of the cortex and extending just through the gray matter, after the manner Smith describes. My experienceagrees with Professor Smith's in regard to the definiteness with which the area striata can be marked out with the naked eye (see Journ. of Anat. and Phys., vol. 41, p. 240). I have not. controlled the findings with Weigert sections. Starting with the anterior calcarine region and working back through the posterior and external calcarine sulci, these sections were taken at regular intervals, plotted and replaced in order to keep the brain intact. Except in a few poorly preserved brains, the stripe of Gennari showed up so distinctly that there was little trouble in making it out.

The type of the drawings made is shown in fig. 1. The mesial surface of the two slides was carefully drawn by the projection apparatus, then the lobes fitted together, and a third tracing of the sulci was made, looking directly own on the occipital pole, The circle in fig. 1-B shows the area used in the other illustrations. The shaded region is that part of the cortex bearing the stripe of Gennari. The mesial surface drawings of the other brains are not shown, as the extent in the two races is practically the same. 
In studying the series of ten negro brains (figs. 1 to 10) certain points are readily seen in the drawings. First, as Smith pointed out, there is a great variation both in the extent of the area striata on the lateral surface of the brain and in its relation to the sulcus lunatus. The sulcus lunatus tends to be more definite on the left side than on the tight (see figs. 7 and 8). As was noted by Smith, the area may touch the sulcus, but more often does not quite reach it. In the series of ten negro brains, there is a definite lunatus making an anterior boundary for the area striata on the left side in eight cases, and a doubtful one in two (figs. 3 and 9). In fig. 3 the limiting sulcus $(X)$ is slightly farther from the area striata; while in fig. 9 it is very small. On the right side there is a definite lunatus in three brains, figs., 1,4 and 6 , a possible one in four, figs. $2,5,9$, and 10 , while in three, figs. 3,7 and 8 , no definite lunatus in made out. Fig. 10 is from a mulatto.

In the series of six white brains, the area striata on the lateralsurface is somewhat less extensive than in the negro series. The presence of a sulcus lunatus is certainly not as marked as in the other series. In one brain (fig. 16), it is very definite on the right side, and is probaly present in the left, and itisinteresting to note that this is the brain of an undersized man, who from the statements of the hospital history was probably a degenerate. In this case the striated area is much more extensive than in the other white brains. All of the rest must be regarded as having a most indefinite lunatus or none. The unbroken extension of the posterior calcarine sulcus to the lateral surface, though present in several instances at least on one side, is less often noted than in the negro series. There are in several instances crescentic folds in these white brains which might possibly be considered the lunatus. I have not so classified them because they are some distance from the area and bear no constant relation to it and hence, in my judgment, should not be classed as the sulcus lunatus.

Duckworth, ${ }^{5}$ in his article on the brains of aboriginal natives of Australia, found that the retrocalcarine sulcus was continued to the lateral aspect of the hemisphere in 37.5 per cent of the cases.

"Duckworth. Brains of the aboriginal natives of Australia. Journ Anat. and Phys., January, 1909. 
This extension he regards as a simian characteristic. He finds it occurs much more often on the left side than on the right. The simian sulcus, occipitalis lunatus, is more frequently found on this side also. These same facts have been observed in my series of negro brains.

From this limited series it would seem that the sulcus lunatus is often the anterior limit of the visual cortex on the lateral surface of the brain but cannot be regarded as nearly so constant as the relations of the calcarine fissure and retrocalcarine sulcus. In contrasting the two series for racial distinctions, while it is true that the negro series shows a tendency to a more marked lunatus, it cannot be regarded as a racial characteristic since there are negro brains without it, and a white brain with a definite lunatus. This study however, confirms Smith's idea that the above method brings out the variations in the visual area, which, whether racial or individual, it is worth while to investigate. 

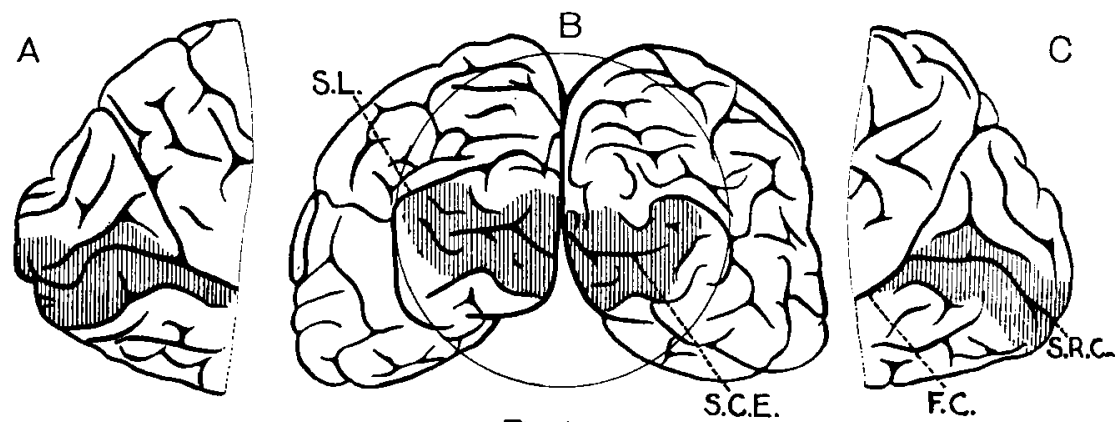

Fig. 1

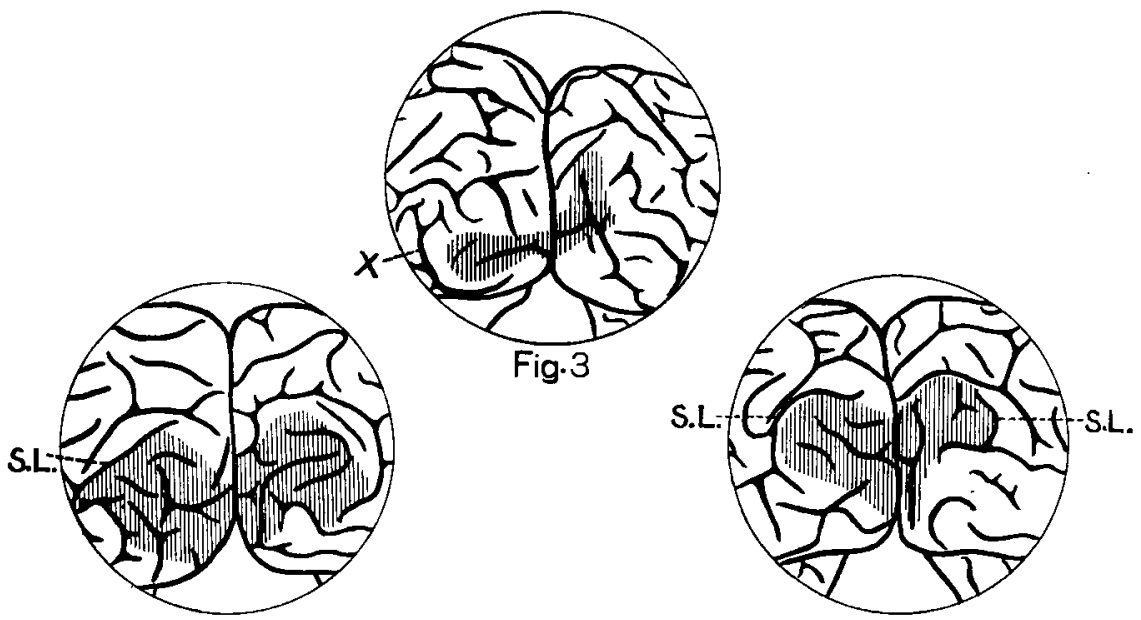

Fig. 2

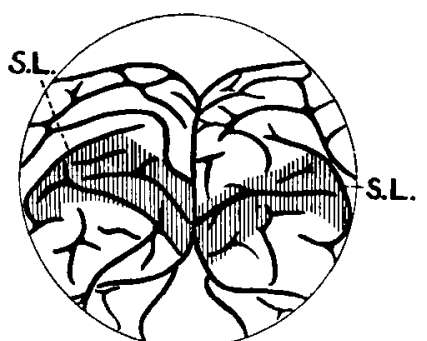

Fig. 6

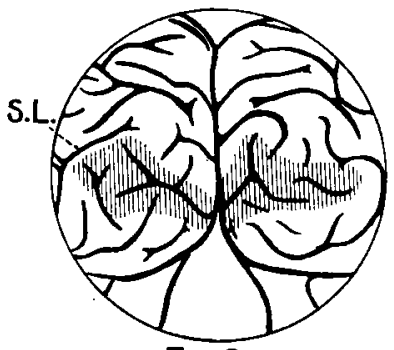

Fig. 5

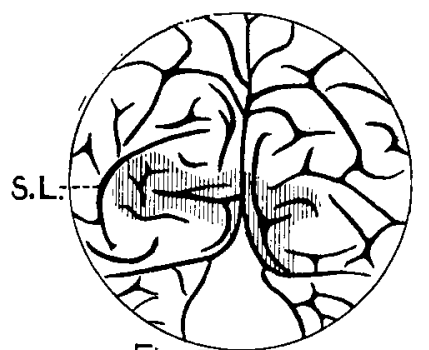

Fig. 7

Fig. 1. Tracings of the occipital lobe showing the area striata (shaded) both on the mesial and lateral surfaces. Brain of a negro (Col. To. 3027).

F. C., fissura calcarina; S. R. C. sulcus retrocalcarinus; S. C.E., sulcus calcarinus externus; S. L., sulcus lunatus.

Figs. 2 to 10 . Tracings of the occipital pole of negro brains, showing the area striata on the lateral surface.

S. L. sulcus lunatus; $\mathbf{X}$, a possible sulcus lunatus. 


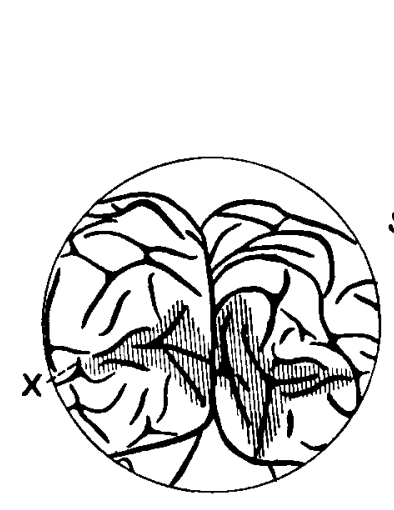

Fig. 9

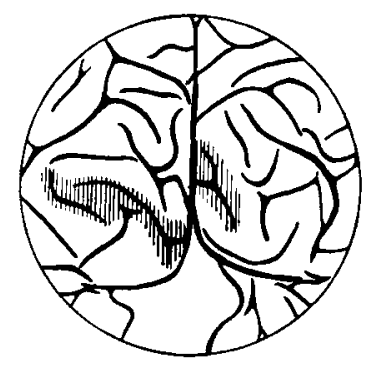

Fig. 12

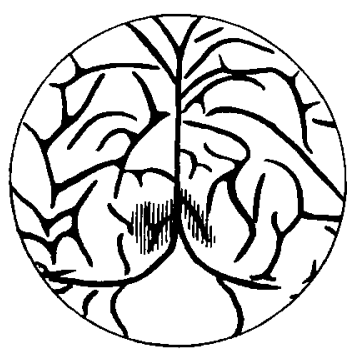

Fig. 15

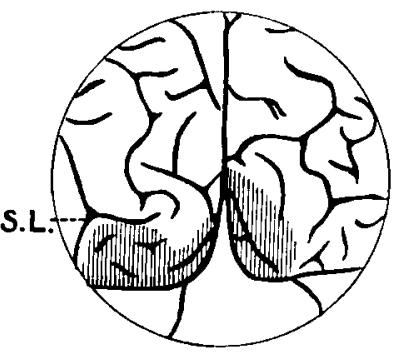

Fig. 8

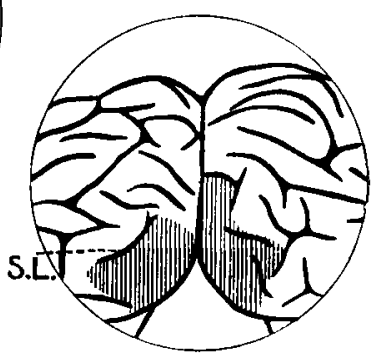

Fig. 10

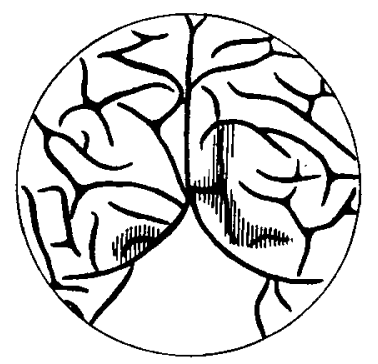

Fig.13

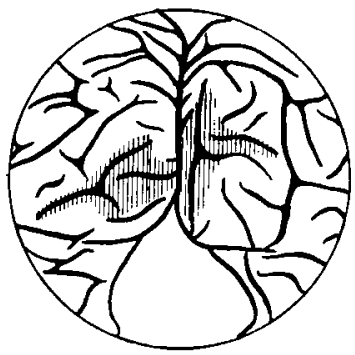

Fig. 11

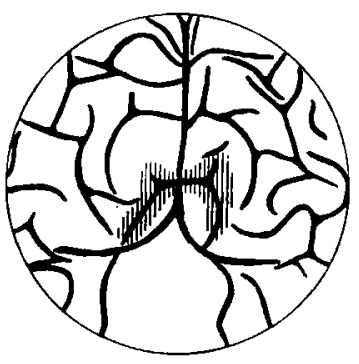

Fig. 14

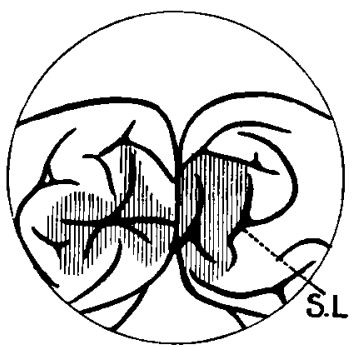

Fig.16

Figs. 11 to 16. Tracings of the occipital pole of white brains, showing the area striata on the lateral surface.

S. L., sulcus lunatus. 